\title{
Agency in earth system governance: refining a research agenda
}

\author{
Eleni Dellas $\cdot$ Philipp Pattberg • Michele Betsill
}

Accepted: 20 December 2010/Published online: 9 February 2011

(C) The Author(s) 2011. This article is published with open access at Springerlink.com

\begin{abstract}
In the face of global environmental change, a key question for the social sciences is how to organize the co-evolution of societies and their natural environment. In this context, a new long-term research program, the Earth System Governance Project, proposes several key issues to be examined: architecture, agency, adaptiveness, accountability, and allocation and access. The contributions to this special issue have focused on the analytical problem of agency. For example, they have examined newly emerging or understudied agents of global environmental governance, or offered a fresh assessment of agency in the context of existing governance mechanisms such as the Clean Development Mechanism. This concluding article outlines several insights provided by the contributions to this special issue regarding four key questions underlying the study of agency in global environmental governance. First, they call attention to the ingredients or processes that characterize agency in the first place and thus distinguish actors from agents. Secondly, the authors highlight the differences among agents and how they interact with each other. Thirdly, they point toward variation in the ways that agents may acquire authority. Finally, the contributions to this special issue suggest that there may be several approaches to evaluating agency, with different consequences. Thus, taken together, the contributions to this special issue provide a starting point for broadening our understanding of agency in earth system governance.
\end{abstract}

Keywords Agency · Earth system governance - Social entrepreneurs · Clean Development Mechanism · Global environmental consultancies

E. Dellas $(\square) \cdot$ P. Pattberg

Institute for Environmental Studies, VU University Amsterdam, De Boelelaan 1087, 1081 HV Amsterdam, The Netherlands

e-mail: eleni.dellas@ivm.vu.nl

P. Pattberg

e-mail: philipp.pattberg@ivm.vu.nl

M. Betsill

Department of Political Science, Colorado State University, Fort Collins, CO 80523, USA

e-mail: m.betsill@colostate.edu 


\section{Abbreviations \\ CDM Clean Development Mechanism}

\section{Introduction}

Global environmental change-that is large-scale changes in the biophysical and biogeochemical environment caused (or influenced) by natural developments and/or human activities - affects the capacity of traditional public actors such as governments to adequately address the emerging challenges of mitigation and adaptation. As a result, global environmental change has triggered the emergence of new actors, as well as shifts in the role and relevance of established ones. Whether states are still able to perform their core functions under the conditions of rapid and large-scale earth system transformation, and to what extent and at what cost non-state actors are complementing or even substituting central governance functions, remain open questions. Such developments have led to an increasing interest in the analytical problem of agency in earth system governance in recent years (Biermann et al. 2009a). For example, the contributions to this special issue have demonstrated the relevance of both public and private agency in the context of the Clean Development Mechanism (CDM), and the ways in which global environmental change has encouraged the emergence of new agents such as social entrepreneurs and environmental consultancy firms. At the same time, these agents also shape norms and values, and thus encourage particular perspectives on global environmental change and its solutions, while marginalizing others.

This concluding article identifies some common issues that run throughout the contributions to this special issue and examines their implications for our understanding of agency and its relevance in earth system governance. First, we provide an overview of the state-of-the-art in research related to actors/agents in the global change issue area (see also Biermann and Pattberg 2008). Secondly, we highlight the individual contributions of each article to four guiding questions outlined in our opening editorial to this issue: (1) What is agency for earth system governance? (2) Who are the agents of earth system governance? (3) How is agency exercised in earth system governance? (4) And finally, how can we evaluate the impacts and effects of agents/agency in earth system governance? ${ }^{1}$ By addressing these questions, the contributions to this special issue broaden our understanding of agency in earth system governance. We conclude our contribution by identifying a number of possible directions for refining the research agenda on agency in earth system governance.

\section{Understanding agency in earth system governance}

The analytical problem of agency begins with the assumption that the credibility, stability, adaptiveness, and inclusiveness of earth system governance is affected by a wide range of actors, including national governments and their bureaucracies as well as the growing population of non-state actors, such as environmental organizations, expert networks, and

1 These questions are based on the Science and Implementation Plan of the Earth System Governance Project (Biermann et al. 2009a); see also (Biermann et al. 2010). 
corporations. The latter are particularly important as global environmental change challenges the capacity of traditional state structures to effectively govern, particularly when many of the activities that give rise to global change fall outside the sovereign authority of the state (Biermann and Dingwerth 2004; Bulkeley and Newell 2010; Marauhn 2007). Within this context, a growing number of scholars have voiced their concern about the problem-solving capacity of the state and the international state-system. Increasingly, scholars and practitioners alike acknowledge that solutions to the challenges of global change do not exclusively originate from public sources (governments and international organizations such as the United Nations), but are co-produced by a host of non-state actors whose authority is contested and whose legitimacy is questionable (Bäckstrand and Lövbrand 2006; Cutler et al. 1999; Dingwerth 2007; Hall and Biersteker 2002; Jagers and Stripple 2003; Pattberg 2005a, 2007; Pattberg and Stripple 2008). As a result, the overall architecture of global environmental governance has been described as increasingly fragmented and multi-layered (Biermann et al. 2009), potentially leading to a number of both conflictive and synergetic overlaps and interlinkages that co-determine the problemsolving capacity of the entire global governance system.

Research on agency in earth system governance considers the capacity of public actors (at local, national and international levels) to respond to global change and how this capacity may be changing. In addition, research on agency focuses on the extent to which non-state actors are responding to new governance demands created by earth system transformation. Ultimately, we are concerned with understanding the changing nature of authority in earth system governance and answering the questions of "who governs for whom and how and to what effect?"

Related to this interest in the reconfiguration of authority, the Earth System Governance Project's Science Plan distinguishes between actors and agents in earth system governance. While actors refer to the individuals, organizations, and networks that participate in decision-making processes, agents are actors who have the ability to prescribe behavior (Biermann et al. 2009a, p. 38). Hence, agents are authoritative actors, where authority is understood as the ability to exercise power with legitimacy. This suggests that agency involves a particular relationship between actors and those whom they seek to govern (Avant et al. 2010). In order to become an agent, an actor must make claims as to why they should be empowered to govern. For state actors, such legitimacy claims may rest on their control over the institutions of the state and monopoly on the use of force. For non-state actors, legitimacy claims may appeal to moral arguments, expertise, participation, or problem-solving ability (Avant et al. 2010; Hall and Biersteker 2002). These claims may be accepted formally and explicitly (through delegation) or implicitly and informally (through recognition).

However, the degree to which authority is uncontested in order to qualify as legitimate remains an empirical question. For example, if citizens are unaware of the work of social entrepreneurs or global environmental consultancies even though it may affect them, they cannot give consent. Does such a failure to contest agency nonetheless render it legitimate? Similarly, linking agency to consent raises issues concerning the identification of the actors or groups that need to consent to an agent for it to possess legitimacy. Indeed, a definition of agency that defines it as consensual might exclude any example of agency that is contested and not universally accepted. Furthermore, as will be elaborated later on, the contributions to this special issue also indicate that consent is not the only source of authority and legitimacy for agents in earth system governance. In sum, as Pattberg and Stripple (2008), pp. 273-274 note, agency can be understood as "the capacity of individual and collective actors to change the course of events or the outcome of processes", provided 
that this capacity is based on authority and not brute force. We revisit some of these definitional issues below.

While the concepts of agency and agent have mainly been proposed to describe and analyze who is contributing to earth system governance, they also carry a more theoretical connotation. In principal-agent theory, an agency relation is one "in which a 'principal' delegates authority to an 'agent' to perform some service for the principal" (Kiser 1999, p. 146). Such agency relations exist in a wide variety of contexts, for example, between voters and politicians, employers and employees or shareholders and managers. As Kiser notes (1999, p. 146), the "key feature of all agency relations is that once principals delegate authority to agents, they often have problems controlling them...". While principal-agent theory might shed some light on specific agents in earth system governance, for example international bureaucracies (see Biermann and Siebenhüner 2009), agents and agency in earth system governance, in our understanding, should not be seen as depending on principals per se. A number of agents acquire authority without being formally delegated with this authority. For example, social entrepreneurs do not act on behalf of a concrete principal, but attempt to influence the outcome of earth system governance as independent agents.

Related to this point, in our understanding, agency "is neither fully located in the public sphere of governments and intergovernmental organizations nor in the private sphere of non-governmental organizations and business actors. It rather emerges in different geographies and at different times as a crucial mix of public and private resources, roles and responsibilities" (Stripple and Pattberg 2010, p. 138). Furthermore, agents contribute to earth system governance indirectly by influencing the decisions of others, or directly by steering those who have given their consent to be governed (implicitly or explicitly). Research on agency thus asks: who are the agents of earth system governance, how do they become authoritative, and to what effect?

Previous research on global environmental governance that is of relevance for the analytical perspective of agency includes at least three areas of concern. First, a broader theoretical debate has emerged about the usefulness of distinguishing between public and private modes of governance and adequate typologies reflecting this distinction (Pattberg and Stripple 2008; Andonova et al. 2009; Stripple and Pattberg 2010). Pattberg and Stripple (2008) have proposed to map environmental governance arrangements according to the actor constellation and the primary mode of governance employed. While actor constellations range from purely public to hybrid and exclusively private, modes of governance include networks and markets in addition to hierarchical steering (in the form of government and intergovernmental organizations) (Pattberg and Stripple 2008, p. 373). Alternatively, Andonova et al. (2009) have introduced a typology of transnational governance that differentiates between actor constellations and the governance functions of information provision, capacity building and implementation, and rule-setting. The contributions to this special issue also address the challenge of distinguishing between different typologies of agents, as they include various examples of agency exercised through different modes of governance, such as, private, public, or hybrid governance; networked, market-driven, or community-based governance.

Second, empirical research has focused on the influence of non-governmental organizations in international decision-making processes (Betsill and Corell 2008). Based on a long-standing debate about the increased relevance of non-state actors in global politics (Arts et al. 2001; Hall and Biersteker 2002; Higgott et al. 2000), scholars have been interested in the conditions of effective non-state influence in international negotiations. A corresponding research line has addressed the autonomous influence of non-state actors 
such as global corporations (e.g. Falkner 2007) and international bureaucracies (Biermann and Siebenhüner 2009) on global politics. The proliferation of non-state actors and their measurable influences in earth system governance has resulted in a sustained debate about the relevance of the state under the conditions of earth system transformation (e.g. Biermann and Dingwerth 2004; Mathews 1997; Raustiala 1997). The influence of non-state actors is also revisited by the contributions to this special issue, for example through examinations of agency exercised by civil society actors and private corporations.

Third, a number of scholars have recently argued for a re-conceptualization of contemporary global environmental governance in light of an increasing density of borderspanning private and public-private governance mechanisms that aim at independent rulemaking rather than at influencing the decisions of states and international organization (Pattberg and Stripple 2008; Okereke et al. 2009). This "transnationalization" of global environmental governance has also led to increased interest in questions of effectiveness and legitimacy of non-state environmental governance (Bäckstrand 2006; Dingwerth and Pattberg 2007; Fuchs and Kalfagianni 2009; Gulbrandsen 2009). Taken together, these three areas of interest provide ample vantage points for researching agency in earth system governance. In sum, by reflecting on how concrete empirical examples of private or hybrid governance can be analyzed from the perspective of agency, the articles in this special issue not only contribute to broadening our empirical understanding of earth system governance, but also contribute to a renewed theoretical interest in questions of agency within the discipline of International Relations and beyond.

\section{What is agency for earth system governance?}

Before engaging in empirical research on the agents of earth system governance, we must possess a better conceptual understanding of agency, of how agents differ from actors, and what constitutes agency in the context of earth system governance. The term 'agency' is widely used across the social sciences and humanities (Dharwadkar et al. 2000; Eisenhardt 1989; Eisner et al. 1996), and it would be useful to draw on these fields to consider the core elements of agency for earth system governance. For example, how is agency for earth system governance defined? While earlier work on agency in earth system governance has converged toward some agreement on the meaning of agency in this context, a number of questions remain unanswered. Thus, agency could be understood as the capacity to act in the face of earth system transformation or to produce effects that ultimately shape natural processes. Agency in earth system governance may be considered exclusively as contributing to problem-solving, while alternatively, agency could well include the negative consequences of the authority to act. It may be useful to consider agency as a dynamic trait that can be created and lost and to explore how this is shaped by environmental change. If agency is dynamic, is it zero-sum in that as some actors gain agency in a policy domain others lose agency? Or can agency be shared across actors? It is also important to consider the possibility of non-human agency in the realm of earth system governance. In some fields, non-human entities such as technology are considered to have agency. This is particularly relevant for energy technology and infrastructure choices that will have life times of several decades and can create path-dependency and carbon lock-in, thereby limiting the agency of future generations. In short, in a coupled human-natural system, does the natural world exercise or influence agency, and if so how?

The contributions to this special issue address some of these questions. In particular, they highlight a key attribute that distinguishes agents from actors: in addition to proposing 
solutions to environmental problems and implementing them, agents can shape broader norms and values relating to earth system governance. For example, social entrepreneurs (Partzsch and Ziegler 2011) both redefine the state's hydraulic mission to be more inclusive of social and environmental concerns, as well as proposing and implementing concrete solutions to local water use issues. Similarly, global environmental consultancy firms identify environmental problems and develop solutions, but are also influential in outlining what practices and solutions are deemed appropriate in the first place (Bouteligier 2011). And, as discussed by Rindefjäll et al. (2011), in defining the criteria for sustainable development that CDM projects must meet, government bureaucracies in countries such as Chile are able to define to what extent this mechanism is used as a tool for sustainable development, or whether it is instead primarily used to attract investment. This also indicates that agency is not necessarily about problem-solving, but may potentially (and intentionally) also have ambivalent or even undesirable effects on sustainable development. Thus, instead of equating agency with effective problem-solving (which is problematic, as any failed attempt at exercising agency would be excluded, as would agency with unintended side-effects), it might be better to examine and categorize the types of goals that are pursued by agents.

Furthermore, the contributions to this special issue do suggest that, at least to some extent, there may be trade-offs or mutual growth in agency between different actors. The social entrepreneurs studied by Partzsch and Ziegler (2011) may become change agents due to their capacity to respond to the failure of the state in adequately implementing or solving the problems resulting from the dominant water governance paradigm or "mission". Thus, in this case, the work of social entrepreneurs can either undermine the state actors promoting the hydraulic mission, or work in tandem with them. However, agency should not necessarily be understood as a zero-sum game; in fact, new agents can emerge on the scene without diminishing the agency of other established agents. The example of environmental consultancy firms (Bouteligier 2011) illustrates that actors can acquire agency without diminishing the agency of others, for example the large corporations who are the clients of environmental consultancies. Indeed, while environmental consultancy firms may constrain actors by promoting particular standards and best practices, they can also strengthen the agency of others as they increase their capacity to act. The observation that interaction between different agents may mutually enhance their agency is also supported by the case of stakeholder networks in India, where the ties and interactions may increase the capacity of multiple actors in a network to contribute to stronger use of wind power potential in a state (Benecke 2011). Similarly, the social entrepreneurs examined by Partzsch and Ziegler (2011) may function as transition agents, in that a key goal for them is empowering local communities, thus eventually transferring agency to them.

\section{Who are the agents of earth system governance?}

A second fundamental question with regard to agency in earth system governance is the following: who ultimately governs the earth system? We need to go beyond identifying the myriad actors that participate in governance processes related to the earth system and instead focus on how some actors gain and exercise agency. To do so, we need to gain insight into the following questions: How is agency configured in different policy domains related to earth system governance? And is it configured differently at different levels of governance? Who are the key agents in a particular issue area and how are they related to one another? To what extent is the state (at all levels) an agent of earth system governance? 
Are all states agents of earth system governance or does it vary according to broader structures in the international system (for example the North-South divide)? How is the agency of states reconfigured as non-state actors become agents, especially at local, regional and international levels of governance? What broad types of agents are central in the area of earth system governance and can we develop a useful typology? Finally, do elements of the coupled human-natural system such as ecosystems and markets exercise agency in establishing and undertaking earth system governance? Existing research engages with a number of these questions, for example by pointing out how some states may find their autonomy affected to a far greater extent by private governance than others (Falkner 2003). Another key issue that is emphasized throughout the literature is that the ongoing reconfigurations of agency challenge discrete, dichotomous categories, such as "state" and "non-state" and "public" and "private" (Betsill and Bulkeley 2006; Pattberg 2005b; Pattberg and Stripple 2008).

The observation that categories of agents, such as states, business and civil society, are neither distinct nor uniform is further substantiated in several contributions to this special issue. For example, while the key agents examined by Partzsch and Ziegler (2011) — social entrepreneurs - are clearly identified as non-state actors, the authors underline that they cannot be equated with either privatization or market-oriented goals. Thus, while social entrepreneurship is often framed as neo-liberal, they find that even where social entrepreneurs are associated with processes of privatization, this is often a different, more communally focused form of privatization. Such discussions highlight the difficulty not only of advancing our understanding of what non-state actors are, but also distinguishing between different types of non-state actors.

A different example comes from the renewable energy sector in India, in this case the wind power sector. Rather than focusing on individual agents of renewable energy governance such as public actors and corporations, Benecke (2011) argues for a broader understanding of agency by highlighting the networked character of stakeholder relations. On this account, agency emerges out of the cooperation of manifold individual actors, who each become agents in their own right while the network among them predominantly provides the resources through which they develop agency.

The case of the CDM in Chile reminds us that the implications of the governance transformation for the role of the state are also not unambiguous, and furthermore, different states and state agencies may pursue vastly different strategies and outcomes within the context of the CDM (Rindefjäll et al. 2011). Thus, while the CDM is often presented as an example of hybrid governance and increasing involvement of private actors in climate governance, state actors retain a significant role in shaping CDM projects. And, while some states may use it to further goals relating to environmental and social sustainability, others may see it more narrowly as a tool to attract investment. The two contributions focusing on the Clean Development Mechanism also illustrate how state actors shape the framework within which the CDM operates, for example by influencing the extent to which the CDM is a tool for emissions reductions, attracts investment or realizes environmental and social benefits. Nonetheless, within this framework, many more actors exercise agency by influencing the extent to which the CDM potential is used (Benecke 2011). In this way, both state and non-state actors may exercise agency regarding different aspects of the CDM.

In relation to the question of how agency in earth system governance is configured, all contributions to this special issue highlight the crucial mix of public, non-profit, and forprofit motivations in developing norms and implementing concrete solutions. On this account, agency is understood as a relational phenomenon, as it emerges out of the 
interaction of different actors controlling varying resources, rather than being a predefined characteristic of any particular actor. As a consequence, agency cannot be equated with some static quality of an actor, but rather emerges out of the time- and space-specific interaction of various actors.

\section{How is agency exercised in earth system governance?}

We can expect that different agents become authoritative on different grounds, so it is important to inquire into the sources of authority. Research in this area could explore how power and authority are configured across types of governance arrangements as well as the changing nature of state-based power and authority as new actors become agents of earth system governance. Thus, while states are often seen as the ultimate source of power and authority, existing research suggests that there is a need to explore alternative ways of understanding power, for example suggesting that even the recognition of an actor as an "expert" grants authority to some, while excluding others (Okereke et al. 2009). This research question also highlights new forms of governance beyond state-based institutions, which may operate on the basis of different sources and degrees of authority (such as consent from customers or other firms in the field, or recognition via statements made at intergovernmental meetings). These include markets, certification schemes, self-regulation, public-private partnerships, and transnational networks (Bernstein (forthcoming); Bernstein et al. 2010; Betsill and Bulkeley 2006; Dingwerth 2007; Gulbrandsen 2009; Pattberg 2005b).

There is a need to document these various forms of governance through which actors exercise agency and to understand how the process of governing varies across governance architectures, and, as the contributions to this special issue indicate, there are more examples of (potential) agents that are not yet studied to the same extent as some of the above. To do so, we need to better understand the following: What are the conditions for the emergence of agency at different levels and within different architectures? Does agency change over time, and, if so, how does this change occur? What are the drivers of changes in agency? Are they internal to the agent, external, or a combination of the two? What is the relationship between governance as a process and agency?

The contributions to this special issue reiterate that the sources of authority for agents are diverse: while public actors may for example expect their control over state institutions to invest them with authority, private actors may carve out other sources of authority for themselves. In some cases, authority may arise where agents are more participatory, accountable, and inclusive than public actors, for example through their local embeddedness and educational efforts (Partzsch and Ziegler 2011). This case thus illustrates that there is no simple dichotomy between public actors that by default have authority, and nonstate actors that inherently lack it. Instead, as is the case in the communal hydraulic mission, they may have authority precisely because they respond to the shortcomings of the elected government, for example regarding the involvement of local populations.

However, the contributions to this special issue place more emphasis on the capacity of agents to promote change or provide solutions as a source of authority: environmental consultancy firms identify environmental problems and potential solutions (Bouteligier 2011), social entrepreneurs are 'change agents' promoting innovation (Partzsch and Ziegler 2011), and stakeholder networks may acquire authority by effectively and efficiently making use of existing conditions to promote the use of renewable energy (Benecke 2011). 
As this discussion indicates, establishing authority is closely tied to questions of legitimacy. In addition to behavior conforming to accepted norms and procedures (such as participation) and effective and efficient problem-solving, a further source of authority that is highlighted in several contributions to this special issue is the mere recognition of an agent's expertise, knowledge, or innovative capacity. For example, 'social entrepreneurs' may see their authority enhanced by fact that this title is bestowed on them, in addition to the recognition of their work in the form of awards and prizes (Partzsch and Ziegler 2011). Similarly, environmental consultancy firms may gain agency when they are recognized as innovative and knowledgeable (Bouteligier 2011), and participants in stakeholder networks mutually enhance each other's agency by fostering reputation and social capital (Benecke 2011). The importance of recognition cannot be overstated: an environmental consultancy firm, for example, may have substantial knowledge and resources, but unless potential customers acknowledge this and make use of its services, it is quite limited in its ability to influence earth system governance. Thus, in summary, the source of authority underpinning agency may be found in agents' capacity to be more responsive and participatory than public institutions, in the unresponsiveness of state bureaucracies, in effective and efficient problem-solving and finally in their ability to gain the recognition of key audiences as innovative and successful problem-solvers.

Conversely, the state departments in the Chilean case examined by Rindefjäll et al. (2011) are not particularly inclusive (a number of civil society actors, for example, disagree with the strategy promoted by the responsible state actors) and they do not exercise agency to implement change, but rather to protect a narrowly defined national strategy (although the opposite is conceivable too, where a broader definition of sustainable development is adopted). In this case, the source of authority is not clearly related to any of the above examples, but rather the legally binding nature of the sustainable development criteria they develop for CDM projects.

Furthermore, the cases also highlight that while agents have the capacity to shape the governance structures within which they operate, the existing framework and dominant norms also shape their roles and capacities. In this sense, they also respond to broader discussions in the social sciences, such as the "structure-agent" debate (Giddens 1984; Wendt 1999). Thus, as outlined by Rindefjäll et al. (2011), stronger host countries for CDM projects have a greater opportunity to be picky about the social and environmental implications of the projects they attract as they are generally more attractive for investment than the poorest countries, which are instead likely to set lower standards to attract any investment at all. At the same time, the market-based structure of the CDM and the fact that sustainable development is not rewarded also encourages the use of this mechanism as a tool to attract investment. In the case of renewable energy governance in India (Benecke 2011), existing state-market relations and the attributes of individual actors that make up the broader stakeholder network limit the agency in the respective policy field. Finally, the social entrepreneurs discussed by Partzsch and Ziegler (2011) are affected by the currently predominant water governance paradigm. At the same time, these agents also contribute to redefining existing structures, as is particularly well illustrated by the social entrepreneurs reacting to perceived problems in the dominant water governance paradigm. The example of environmental consultancy firms (Bouteligier 2011) also illustrates that multiple structural transformations can be at work, (re-)configuring authority in earth system governance. In this specific case, both the widening and the deepening of the Information Age as well as the increased density of national and international regulatory frameworks have enabled environmental consultancy firms to become agents of earth system governance. 


\section{How can we evaluate agents and agency?}

The effectiveness of different agents and their various means of exercising agency (for example through public-private partnerships or market-based instruments) are not sufficiently understood. Most advances in the study of earth system governance have focused on states as core actors and on intergovernmental forms of cooperation. This leads us to ask the following: How can we assess the effectiveness of different agents and their various means of exercising agency? Can we apply approaches developed in the study of institutions, such as output-outcome-impact, to agency? Should an evaluation of agent effectiveness focus on environmental outcomes, behavioral changes or effects on knowledge and discourse? Can we arrive at a Pareto efficiency of agency? In other words, can we decipher what the optimal number of different agents would be to achieve the highest level of effectiveness in terms of preventing, mitigating or adapting to global environmental change while, at the same time, protecting human livelihoods? In existing studies, agency is rarely evaluated explicitly from the perspective of effectiveness, while a focus on the sources of legitimacy of different agents is prominent (Bäckstrand 2006; Dingwerth 2007).

The cases presented in the contributions to this special issue highlight a number of further challenges that need to be addressed in attempts to assess the effectiveness of different agents and means of exercising agency. The example of the CDM in Chile highlights that while state departments might be the key agents in defining the sustainable development criteria applied to CDM projects, the approach they favor may not necessarily be the most desirable in terms of environmental outcomes (Rindefjäll et al. 2011). If we compare this exercise in agency according to the intended goal of the state actor defining the sustainable development criteria, which in this case is increasing investment, we might very well conclude that it is an effective exercise of agency, as the number of CDM projects in Chile suggests. However, if we compare to a broader definition of sustainable development rather than the one agreed upon nationally, then, in terms of both environmental and social outcomes, this exercise of agency seems less effective. The study on social entrepreneurs (Partzsch and Ziegler 2011) touches on similar questions: in this case, the presence or lack of innovation is the single most relevant criterion defining social entrepreneurs as change agents. However, innovation alone is no guarantee for successful results. While the above examples point to the problem of defining what results are to be deemed successful, agency can also have unintended or negative effects. This issue is in particular raised in the context of environmental consultancy firms, some of which have been accused of issuing assessments or implementing standards that amount to 'greenwash' of unsustainable practices (Bouteligier 2011).

In the case of renewable energy governance in India (Benecke 2011), the case study presented in this special issue has clearly demonstrated that a number of factors determine the effectiveness of renewable energy service delivery. In particular, intensive and wellinstitutionalized state-market relations together with a certain quality of interactions (for example a minimum level of trust among the stakeholders) increase the likelihood of effective implementation. Successful agency is thus dependent on structural factors that are at least partially outside the control of the agents.

However, as the article on environmental consultancies (Bouteligier 2011) confirms, measuring the effectiveness of agency is not an easy task, in particular in the early phase of a developing research program. As agency as an analytical category in earth system governance research is slowly gaining ground, scholars seem to be interested predominantly in indentifying novel agents in earth system governance and the corresponding governance instruments and arrangements (for example, social entrepreneurs and 
environmental consultancy firms). Consequently, the next phase of agency research should focus, at least to some extent, on measuring observable effects of agency in earth system governance. The contributions to this special issue do indicate that outlining the effects of agency is possible, for example by utilizing an output-outcome-impact distinction. This is most explicitly done to illustrate the effects of stakeholder networks in the wind energy sector in India (Benecke 2011), showing, for example, that they may have an influence on framework conditions, which lead to more implementation practices and additional support for wind energy. The activities of social entrepreneurs (Partzsch and Ziegler 2011) also have varied effects, ranging from institutional change, to addressing water access or water pollution, which may be analyzed within such a framework. What is still lacking are broader conceptualizations of the effects of agency in earth system governance that would allow for large-scale comparative assessments across different types of agency.

\section{Conclusion}

The contributions to this special issue advance our understanding of agency in earth system governance by addressing several of the key questions posed in the Science and Implementation Plan of the Earth System Governance project (Biermann et al. 2009) and outlined in more detail in this concluding article. They also provide some practical guidance for scholars conducting research in this field as well as suggestions for future research. In particular, we suggest the following elements as useful starting points for future research on agency in earth system governance.

First, the study of agency in earth system governance requires identifying those actors involved in a decision-making process who actively shape norms and values related to a particular environmental issue, and/or identifying environmental problems and possible solutions. Beginning with a catalog of the actors involved in a particular issue area may be a useful first step, but research must go further and clarify which actors have become authoritative within a given field. A further interesting question in this area concerns the ways in which different agents constrain or enhance each other's agency: as some of the contributions to this special issue indicate, the interactions between agents may go in multiple directions.

Second, on a related note, it would be useful to consider whether there are other aspects to agency beyond shaping norms and values, defining problems and solutions. In any study of agency, it is important to clarify on what basis agency is being identified in order to avoid claims that agency is simply in the eye of the beholder. Scholars should be sure to clearly state the criteria being used to distinguish actors from agents in particular cases of earth system governance so that readers can challenge the assumptions underlying the criteria and/or replicate findings. In addition to having clear criteria for distinguishing agents from actors, researchers also need to be sensitive to varying degrees of agency and the general scope conditions for agency. For example, it may be tempting to identify agents as those actors which have implicit or explicit consent, or to focus on actors with the capacity to contribute to problem-solving. However, focusing on these characteristics would leave a blind spot on examples of failed agency, or unintentionally negative agency. Instead, we need to recognize that the authority of agents can come from other sources as well, and will often be contested.

Third, scholars also need to consider the basis on which agents become authoritative. All contributions to this special issue study examples of agency in earth system governance where authority has been attained through consent that is either granted explicitly or implicitly. Although the empirical studies presented in this special issue did not touch upon 
cases in which coercion is used to attain agency in earth system governance, this possibility should not be entirely disregarded by the researcher. Future studies therefore should attempt to unearth in particular those cases in which influence is achieved through coercion rather than consent. Furthermore, a number of existing studies highlight that the authority and legitimacy of many new, non-state actors in earth system governance remain contested. It would be interesting to see to what extent a lack of legitimacy and consent affects the exercise of agency.

Fourth, the contributions highlight the importance of understanding the interaction between agents and structures, in particular the ways in which structures may enable or constrain the exercise of agency. This line of inquiry could also incorporate issues of scale. As agents contribute to shaping norms and values around an issue area at one level of political jurisdiction, what are the implications at lower levels? Do these structures give rise to new "sub-agents" who may in turn reshape or reinforce existing structures? Possibly, the relationship between state and non-state actors in the case of the CDM can be seen as an example of agents and sub-agents, with the agent (in this case, the state) defining the overall national framework for the CDM, while various sub-agents (state and non-state actors) are responsible for the results that are achieved within this framework. In addition, an attention to issues of scale could also address the question at which level of governance agency is exercised most effectively.

Finally, future studies of agency in earth system governance should give careful consideration to ways of evaluating the effectiveness of agents in earth system governance, as this field of inquiry is a gap in current research. The contributions to this special issue indicate that agency in earth system governance can not only be ineffective, but also have negative implications or be used for goals other than addressing environmental change. In particular, they highlight some of the challenges involved in conducting such evaluations, which are perhaps similar to some of the early debates in evaluating the effectiveness of international regimes. Particularly important in this respect are the criteria used for evaluating the effectiveness of agency: as the case of the CDM in Chile indicates, whether we evaluate on the basis of goal attainment or successful problem-solving may lead to vastly different evaluations of effectiveness. Future research could consider whether and how developments from that literature can be used to strengthen evaluations of effectiveness in the exercise of agency in earth system governance.

To conclude, research on agency in earth system governance, that is the multiple ways in which actors acquire authority to affect the outcomes of earth system governance, is an emerging field of inquiry within the larger attempt to understand the human dimensions of global environmental change. Taken together, this special issue provides a starting point for broadening our understanding of agency in earth system governance. While many aspects of the concept of agency and its application to the field of earth system governance will remain fuzzy and ambiguous in this early stage of the research program, we believe that this special issue provides valuable vantage points, in the form of questions to be asked, concepts to be explored and perspectives to be applied, for a fruitful exploration of agency in earth system governance in the years to come.

Open Access This article is distributed under the terms of the Creative Commons Attribution Noncommercial License which permits any noncommercial use, distribution, and reproduction in any medium, provided the original author(s) and source are credited. 


\section{References}

Andonova, L. B., Betsill, M. M., \& Bulkeley, H. (2009). Transnational climate governance. Global Environmental Politics, 9, 52-73.

Arts, B., Noortmann, M., \& Reinalda, B. (Eds.). (2001). Non-state actors in international relations. Aldershot: Ashgate.

Avant, D. D., Finnemore, M., \& Sell, S. K. (2010). Who governs the globe? In D. D. Avat, M. Finnemore, \& S. K. Sell (Eds.), Who governs the globe? (pp. 1-31). Cambridge: Cambridge University Press.

Bäckstrand, K. (2006). Multi-stakeholder partnerships for sustainable development: Rethinking legitimacy, accountability and effectiveness. European Environment, 16, 290-306.

Bäckstrand, K., \& Lövbrand, E. (2006). Planting trees to mitigate climate change: Contested discourses of ecological modernization, green governmentality and civic environmentalism. Global Environmental Politics, 6, 50-75.

Benecke, E. (2011). Networking for climate change: Agency in the context of renewable energy governance in India. International Environmental Agreements: Politics, Law and Economics, 11.. doi: 10.1007/s10784-011-9148-8.

Bernstein, S. (forthcoming). Legitimacy in intergovernmental and non-governmental global governance. Review of International Political Economy.

Bernstein, S., Betsill, M., Hoffmann, M. J., \& Paterson, M. (2010). A tale of two Copenhagens: Carbon markets and climate governance. Millennium: Journal of International Studies, 39, 161-173.

Betsill, M. M., \& Bulkeley, H. (2006). Cities and the multilevel governance of global climate change. Global Governance, 12, 141-159.

Betsill, M. M., \& Corell, E. (Eds.). (2008). NGO diplomacy: The influence of non-governmental organizations in international environmental negotiations. Cambridge, MA: MIT Press.

Biermann, F., \& Dingwerth, K. (2004). Global environmental change and the nation state. Global Environmental Politics, 4, 1-22.

Biermann, F., Betsill, M. M., Gupta, J., Kanie, N., Lebel, L., Liverman, D., Schroeder, H., Siebenhüner, B., (with contributions from Conca, K., da Costa Ferreira, L., Desai, B., Tay, S. \& Zondervan, R.) (2009a). Earth system governance: people, places and the planet. Science and implementation plan of the earth system governance project. Earth System Governance Report 1, IHDP Report 20. Bonn: IHDP.

Biermann, F., \& Pattberg, P. (2008). Global environmental governance: Taking stock, moving forward. Annual Review of Environment and Resources, 33, 277-294.

Biermann, F., \& Siebenhüner, B. (Eds.). (2009). Managers of global change: The influence of international environmental bureaucracies. Cambridge, MA: MIT Press.

Biermann, F., Pattberg, P., van Asselt, H., \& Zelli, F. (2009). The fragmentation of global governance architectures: A framework for analysis. Global Environmental Politics, 9, 14-40.

Biermann, F., Betsill. M. M., Gupta, J., Kanie, N., Lebel, L., Liverman, D., Schroeder, H., Siebenhüner, B., \& Zondervan, R. (2010). Earth system governance: A research framework. International Environmental Agreements: Politics, Law and Economics, 10, 277-298.

Bouteligier, S. (2011). Exploring the agency of global environmental consultancy firms in earth system governance. International Environmental Agreements: Politics, Law and Economics, 11. doi: 10.1007/s10784-011-9149-7.

Bulkeley, H., \& Newell, P. (2010). Governing climate change. London: Routledge.

Cutler, C. A., Haufler, V., \& Porter, T. (Eds.). (1999). Private authority and international affairs. Albany: State University of New York Press.

DiMaggio, P. J., \& Powell W.W. (1991), The new institutionalism in organizational analysis. Chicago: Chicago University Press.

Dharwadkar, R., George, G., \& Brandes, P. (2000). Privatization in emerging economies: An agency theory perspective. Academy of Management Review, 25, 650-669.

Dingwerth, K. (2007). The new transnationalism: Transnational governance and democratic legitimacy. Basingstoke, UK: Palgrave.

Dingwerth, K., \& Pattberg, P. (2007). Wirkungen Transnationaler Umweltregime. Politische Vierteljahresschrift, PVS, 39, 133-156.

Eisenhardt, K. M. (1989). Agency theory: an assessment and review. Academy of Management Review, 14, 57-74.

Eisner, M. A., Worsham, J., \& Ringquist, E. (1996). Crossing the organizational void: The limits of agency theory in the analysis of regulatory control. Governance: An International Journal of Policy and Administration, 9, 407-428.

Falkner, R. (2003). Private environmental governance and International Relations: Exploring the links. Global Environmental Politics, 3, 72-87. 
Falkner, R. (2007). Business power and conflict in international environmental politics. Basingstoke: Palgrave Macmillan.

Fuchs, D., \& Kalfagianni, A. (2009). Private food governance and implications for social sustainability and democratic legitimacy. In P. Utting (Ed.), Business, social policy and corporate political influence in developing countries. United Nations Research Institute for Social Development (UNRISD) (pp. 225-247). New York: Palgrave Macmillan.

Giddens, A. (1984). The constitution of society: Outline of the theory of structuration. Berkeley: University of California Press.

Gulbrandsen, L. H. (2009). The emergence and effectiveness of the Marine Stewardship Council. Marine Policy, 33, 654-660.

Hall, R. B., \& Biersteker, T. J. (Eds.). (2002). The emergence of private authority in global governance. Cambridge: Cambridge University Press.

Higgott, R. A., Underhill, G., \& Bieler, A. (Eds.). (2000). Non-state actors and authority in the global system. London, New York: Routledge.

Jagers, S., \& Stripple, J. (2003). Climate governance beyond the state. Global Governance, 9, 385-399.

Kiser, E. (1999). Comparing varieties of agency theory in economics, political Science, and sociology: An illustration from state policy implementation. Sociological Theory, 17, 146-170.

Marauhn, T. (2007). The changing role of the state. In D. Bodansky, J. Brunnée, \& E. Hey (Eds.), Oxford handbook of international environmental law (pp. 727-748). New York: Oxford University Press.

Mathews, J. (1997). Power shift. Foreign Affairs, 76, 50-66.

Okereke, C., Bulkeley, H., \& Schroeder, H. (2009). Conceptualizing climate governance beyond the international regime. Global Environmental Politics, 9, 58-78.

Partzsch, L., \& Ziegler, R. (2011). Social entrepreneurs as change agents. A case study on power and authority in the water sector. International Environmental Agreements: Politics, Law and Economics, 11. doi:10.1007/s10784-011-9150-1.

Pattberg, P. (2005a). The institutionalization of private governance: How business and Non-profit organizations agree on transnational rules. Governance: An International Journal of Policy, Administration, and Institutions, 18, 589-610.

Pattberg, P. (2005b). The forest stewardship council: Risk and potential of private forest governance. Journal of Environment and Development, 14, 256-374.

Pattberg, P. (2007). Private institutions and global governance. The new politics of environmental sustainability. Cheltenham, UK and Northampton, MA: Edward Elgar.

Pattberg, P., \& Stripple, J. (2008). Beyond the public and private divide: Remapping transnational climate governance in the 21st century. International Environmental Agreements: Politics, Law and Economics, 8, 367-388.

Raustiala, K. (1997). States, NGOs, and international environmental institutions. International Studies Quarterly, 41, 719-740.

Rindefjäll, T., Lund, E., \& Stripple, J. (2011). Wine, fruit and emission reductions: The CDM as development strategy in Chile. International Environmental Agreements: Politics, Law and Economics, 11. doi:10.1007/s10784-011-9151-0.

Stripple, J., \& Pattberg, P. (2010). Agency in global climate governance: Setting the stage. In F. Biermann, P. Pattberg, \& F. Zelli (Eds.), Global climate governance beyond 2012: Architecture, agency and adaptation (pp. 137-145). Cambridge: Cambridge University Press.

Wendt, A. (1999). Social theory of international politics. Cambridge: Cambridge University Press. 